\title{
The Epigenetic and Metabolic Language of the Circadian Clock
}

\author{
Paolo Sassone-Corsi
}

\begin{abstract}
The circadian clock controls a large variety of neuronal, endocrine, behavioral and physiological responses in mammals. This control is exerted in large part at the transcriptional level on genes expressed in a cyclic manner. A highly specialized transcriptional machinery based on clock regulatory factors organized in feedback autoregulatory loops governs a significant portion of the genome. These oscillations in gene expression are paralleled by critical events of chromatin remodeling that appear to provide plasticity to circadian regulation. Specifically, the NAD ${ }^{+}$-dependent deacetylases SIRT1 and SIRT6 have been linked to circadian control of gene expression. This and additional accumulating evidence shows that the circadian epigenome appears to share intimate links with cellular metabolic processes and has remarkable plasticity, showing reprogramming in response to nutritional challenges. In addition to SIRT1 and SIRT6, a number of chromatin remodelers have been implicated in clock control, including the histone H3K4 tri-methyltransferase MLL1. Deciphering the molecular mechanisms that link metabolism, epigenetic control and circadian responses will provide valuable insights towards innovative strategies of therapeutic intervention.
\end{abstract}

\section{Introduction}

Metabolism, homeostatic balance and behavior follow the 24-h daily cycle (EckelMahan and Sassone-Corsi 2013). Circadian rhythms are virtually present in all life forms on our planet, including mammals, insects, plants, fungi and cyanobacteria. In higher organisms, circadian rhythms have evolved into a complex physiological and molecular system demonstrated by sleep-wake cycles, daily fluctuations in body temperature, blood pressure, cellular regeneration and behavior such as food

\footnotetext{
P. Sassone-Corsi $(\bowtie)$

Department of Biological Chemistry, Center for Epigenetics and Metabolism, Unit 904 of INSERM, University of California, Irvine, Irvine, CA 92697, USA

e-mail: psc@uci.edu 
intake and alertness levels (Asher and Sassone-Corsi 2015). Metabolism, nutritional intake and body homeostasis are also under circadian control, displaying rhythms in the levels of circulating hormones and metabolites, as well as enzymes within the biochemical pathways participating in their biosynthesis (Eckel-Mahan and Sassone-Corsi 2013; Gamble et al. 2014). Circadian rhythms are so intimately linked to biological processes that their misregulation may lead to a number of pathologies such as obesity, metabolic syndrome, diabetes, cardiovascular diseases, inflammation, sleep disorders and some cancers (Eckel-Mahan and Sassone-Corsi 2013).

The molecular bases of circadian rhythms have been explored, revealing a remarkable variety of molecular mechanisms that underlie clock function. An important system of circadian control utilizes the core clock molecular machinery that consists of transcription factors and regulators, both activators and repressors, that act in concert to drive circadian expression of an important fraction of the genome. A number of high-throughput transcriptome profiling studies have established that 15-30\% of all transcripts are controlled by the clock, depending on the tissue or cell type (Duffield et al. 2002; Panda et al. 2002; Storch et al. 2002; Ueda et al. 2002). Accumulating evidence has shown that this global program of gene expression is achieved through events of cyclic chromatin remodeling and epigenetic control.

\section{Chromatin Remodeling, Cyclic Transcription and the Clock}

The molecular organization of the circadian system relies on a network of cellular oscillators present in virtually every cell of the organism. An intricate network of transcriptional-translational feedback loops constitutes the molecular clock (EckelMahan and Sassone-Corsi 2013; Zhang and Kay 2010). The basic helix-loop-helix (b-HLH)-PAS proteins CLOCK and BMAL1 are core elements of this system and function as transcriptional activators to drive the expression of many clockcontrolled genes (CCGs). CLOCK and BMAL1 heterodimers bind E-boxes in CCG promoters and activate their expression. Among the CCGs there are genes encoding other core clock protein repressors Period (PER1-3) and Cryptochromes (CRY1-2). PER and CRY proteins heterodimerize in the cytoplasm and translocate to the nucleus to inhibit CLOCK:BMAL1-mediated transcription. The stability of PER:CRY complexes is regulated by posttranscriptional modifications (Lee et al. 2009) and ubiquitination events (Busino et al. 2007; Hirano et al. 2013; Siepka et al. 2007; Yoo et al. 2013). The time-controlled clearance of the repressors primes for a the next cycle of CLOCK:BMAL1-driven gene activation. This system then leads to the cyclic activation of other regulatory pathways generating interconnected transcriptional feedback loops. These provide remarkable plasticity to the circadian system, eliciting multiple daily oscillations in the transcriptome (Masri and Sassone-Corsi 2010). 
Specific cyclic chromatin transitions occur in a genome-wide scale and are associated with circadian waves of transcription (Masri and Sassone-Corsi 2010). Several chromatin remodelers have been found to be involved in circadian control. The protein CLOCK was found to operate as an acetyltransferase on histone H3 at K9 and K14 (Doi et al. 2006), modifications associated with a chromatin state permissive for transcription. CLOCK acts in concert with other histone acetyltransferases (HATs) (Etchegaray et al. 2003), such as CBP (CREB binding protein), p300 and with the CBP-associated factor PCAF (Lee et al. 2010; Curtis et al. 2004; Takahata et al. 2000). A number of histone deacetylases (HDACs) have been found to counterbalance these HATs. For example, the circadian repressor PER recruits SIN3A-HDAC1 (Duong et al. 2011), whereas the protein CRY1 associates with the complex SIN3B-HDAC1/2 (Naruse et al. 2004). The circadian regulator REV-ERB $\alpha$ recruits the NCoR-HDAC 3 complex in a rhythmic manner to chromatin via a process that has been linked to the control of lipids metabolism in the liver (Sun et al. 2011). Thus, a variety of circadian repressive complexes appear to exist that may elicit distinct functions at unique times of the circadian cycle. The nicotinamide adenine dinucleotide $\left(\mathrm{NAD}^{+}\right)$-dependent class III of HDACs was found to play a critical role in connecting cellular metabolism to circadian physiology. The founding member, SIRT1, gives the name to this class of enzymes, collectively known as sirtuins. There are seven sirtuins, all involved in various aspects of metabolism, inflammation and aging; their intracellular localization is nuclear, cytoplasmic or mitochondrial. The nuclear proteins SIRT1 and SIRT6 have been shown to contribute to circadian transcription (Nakahata et al. 2008; Masri et al. 2014).

A number of chromatin post-translational modifications have been linked to clock function in addition to acetylation. The first evidence that a histone modification may play a role in circadian transcription was the light-inducible phosphorylation at H3-S10 in SCN neurons (Crosio et al. 2000). The activating histone methylation H3K4me3 has also been linked to clock control and it seems to be essential to permit circadian chromatin transitions that lead to activation of CCG expression (Ripperger and Schibler 2006). MLL1, a H3K4 histone methyltransferase (HMT), was shown to elicit CLOCK:BMAL1 recruitment to chromatin at specific circadian promoters and for the cyclic tri-methylation at H3K4 (Katada and Sassone-Corsi 2010). Also the repressive mark H3K27me3 is clock controlled at the Perl promoter through a mechanism that involves the methyltransferase EZH2 (Etchegaray et al. 2006). Additional chromatin remodelers involved in circadian function include the demethylase JARID1a that appears to inhibit HDAC1, thereby enhancing CLOCK:BMAL1-mediated transcription (DiTacchio et al. 2011), and the FAD (Flavin Adenine Dinucleotide)-dependent demethylase LSD1 whose function is controlled by PKC $\alpha$-mediated circadian phosphorylation (Nam et al. 2014). 


\section{Cellular Metabolism and the Circadian Clock Converge}

A large number of human studies and animal models provide solid evidence of the reciprocal regulation between the circadian clock and cellular and organismal homeostasis (Eckel-Mahan and Sassone-Corsi 2013; Dallmann et al. 2012; EckelMahan et al. 2012, 2013; Hatori et al. 2012; Kasukawa et al. 2012). The clock regulates metabolism by controlling the expression of a large fraction of the genome. Moreover, the oscillator appears to sense the cellular energy state and consequently adapts its function accordingly.

Several levels of interplay exist between cellular metabolism and chromatin remodeling (Masri and Sassone-Corsi 2010; Feng and Lazar 2012; Katada et al. 2012). Acetylation of histones or non-histone nuclear proteins depends on the supply of acetyl-CoA in the nuclear compartment. The main carbon source in mammals is glucose, which generates acetyl-CoA because of the enzyme adenosine triphosphate (ATP)-citrate lyase (ACLY). ACLY protein levels are cyclic in the liver (Mauvoisin et al. 2014), and ACLY activity controls global histone acetylation depending on glucose availability (Wellen et al. 2009). Thus, circadian changes in histone acetylation are controlled not only by specific HATs but also by interconnected metabolic pathways and enzymes supplying nuclear acetyl-CoA. A similar regulation involves S-adenosyl methionine (SAM), the metabolite used by methyltransferases to deliver methyl groups. Changing SAM levels directly influence H3K4me3 levels in mouse pluripotent stem cells (Shyh-Chang et al. 2013). Also, treatment with 3-deazaadenosine (DAA), an inhibitor of SAH (S-adenosylhomocysteine) hydrolysis that hinders transmethylation, elongates the circadian period (Fustin et al. 2013). Further research is necessary to decipher the impact of one carbon metabolism in the circadian transcriptome.

Nicotinamide adenine dinucleotide $\left(\mathrm{NAD}^{+}\right)$is a pivotal metabolite for the circadian epigenome. $\mathrm{NAD}^{+}$shows robust diurnal rhythms in synchronized cells and mice (Bellet et al. 2013; Nakahata et al. 2009; Ramsey et al. 2009), and operates as a cofactor for class III of HDACs, the sirtuins (see next section).

The core machinery may be directly influenced by changing metabolic states. Specifically, the DNA-binding function of NPAS2:BMAL1 and CLOCK:BMAL1 heterodimers was shown to be influenced by the redox states of NAD $(H)$ or NADP (H) (Rutter et al. 2001). This finding implied that CLOCK:BMAL1 transcriptional activity should be sensitive to the levels of cellular redox. While a causal evidence for this regulation has not been explored, circadian oscillations in intracellular redox potentials are evolutionary conserved (Eckel-Mahan and Sassone-Corsi 2013; Asher and Sassone-Corsi 2015). Thus, while the ability of NPAS2 or CLOCK to sense the intracellular redox state in vivo remains to be proven, independent evidence provides interesting information. Indeed, crystallographic analyses of the CRY1-PER2 complex indicate that a disulfide bond between two cysteine residues in CRY1 weakens its interaction with PER2, whereas a reduced state of CRY1 stabilizes the complex and facilitates transcriptional repression (Schmalen et al. 2014). In this scenario, CRY2 would retain specific FAD (Flavin 
Adenine Dinucleotide) binding activity, and FAD competes for CRY2 binding pocket with the ubiquitin ligase complex $\mathrm{SCF}^{\mathrm{FBXL} 3}$, which has been shown to control period length by regulating CRYs stability (Xing et al. 2013). Interestingly, this finding provides a possible approach to pharmacologically adjust circadian period length by using small molecules resembling FAD (Hirota et al. 2012).

Posttranslational modifications of clock proteins have been shown to modify their regulatory capacity. For example, CLOCK, BMAL1 and PER2 can be O-linked $N$-acetylglucosamine (GlcNAc)-modified by the enzyme O-GlcNAc transferase (OGT), which results in a change in their activities (Kaasik et al. 2013; Li et al. 2013). Importantly, liver-specific ablation of OGT leads to dampened oscillation of Bmall and gluconeogenic genes. Thus, glucose levels dictate the availability of GlcNAc, OGT serving as a signal transducer between cellular metabolism and circadian components. Along the same lines, phosphorylation of CRY1 by the nutrient sensor kinase AMPK (AMP-activated protein kinase) connects cellular energy levels with the circadian clock by adjusting it to the changing intracellular ratio of AMP/ATP (Jordan and Lamia 2013; Gomes et al. 2013).

\section{The Central Role of Sirtuins}

The intracellular availability in time and space of specific metabolites constitutes an intriguing level of control for their protein sensors (Katada et al. 2012). In this respect, the circadian oscillation in $\mathrm{NAD}^{+}$concentration represents a revealing paradigm. The $\mathrm{NAD}^{+}$biosynthetic salvage pathway controls the conversion of nicotinamide (NAM) to $\beta$-nicotinamide mononucleotide (NMN); this step is catalyzed by a rate-limiting step enzyme, the nicotinamide phosphoribosyltransferase (NAMPT, also known as visfatin). The circadian machinery controls the transcription of the Nampt gene through direct binding of CLOCK:BMAL1 to E-boxes in the promoter (Nakahata et al. 2009; Ramsey et al. 2009). NMN is converted to NAD ${ }^{+}$ by the enzymes nicotinamide mononucleotide adenylyltransferase 1-3 (NMNAT13) (Fig. 1). Thus, a transcriptional-enzymatic feedback loop controls $\mathrm{NAD}^{+}$biosynthesis and availability that in turn could result in circadian function of a variety of $\mathrm{NAD}^{+}$-dependent enzymes. Moreover, there is a differential regulation of $\mathrm{NAD}^{+}$ levels and $\mathrm{NAD}^{+}$-consuming enzymes in various cell compartments (Gomes et al. 2013; Yang et al. 2007). In this respect the sirtuins deserve special attention. Indeed, of the seven mammalian sirtuins, three (SIRT1, SIRT3 and SIRT6) have been functionally linked to circadian control and found to modulate cyclic outputs in response to metabolic cues.

SIRT3 is a mitochondrial enzyme that displays robust changes in its deacetylase activity in response to $\mathrm{NAD}^{+}$levels (Hebert et al. 2013; Peek et al. 2013; Masri et al. 2013). SIRT3 controls mitochondrial function, including fatty acid oxidation and intermediary metabolism, by directly targeting rate-limiting enzymes for mitochondrial biochemical processes (Peek et al. 2013). As mitochondrial fatty acid 

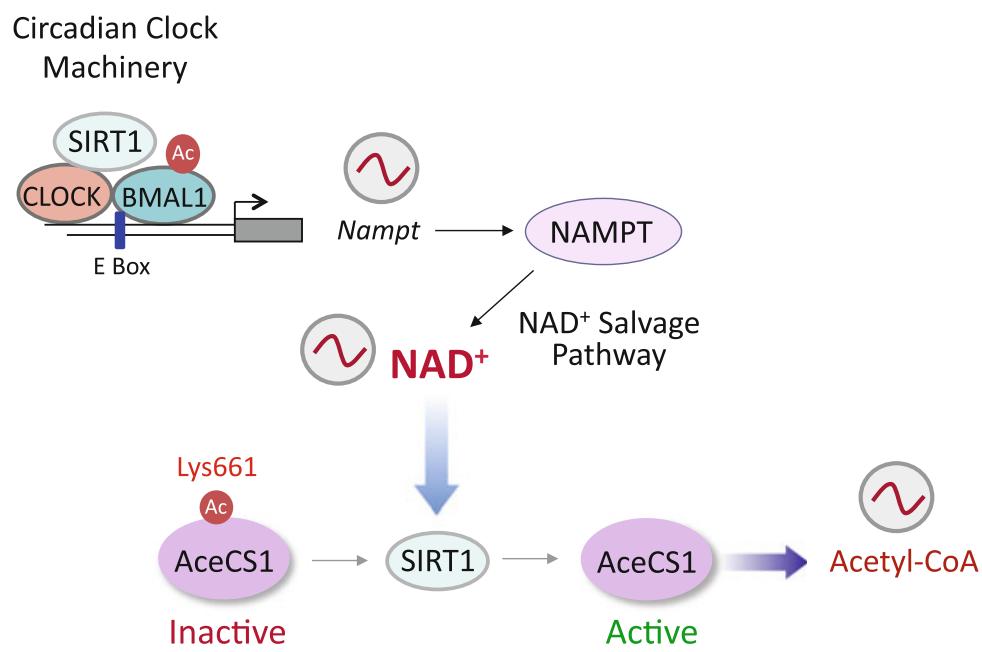

Fig. 1 Metabolism and the circadian clock converge. A paradigm example is represented by the role of SIRT1 and other sirtuins in clock regulation. The circadian machinery controls a large fraction of the genome through the transcriptional regulation of CCGs. One of the CCGs is the gene encoding the protein NAMPT, the rate-limiting enzyme in the $\mathrm{NAD}^{+}$-salvage pathway. Cyclic transcriptional control of the Nampt gene results in the cyclic synthesis of NAD ${ }^{+}$, which in turn is consumed rhythmically by enzymes such as SIRT1, whose deacetylase activity is consequently cyclic. One of the non-histone targets is the enzyme AceCS1, which contributes to the synthesis of Acetyl-CoA. AceCS1 is acetylated at one residue, Lys661, and its cyclic deacetylation by SIRT1 activates the enzyme, resulting in cyclic synthesis of Acetyl-CoA and thereby oscillating availability of acetyl groups required for global acetylation

oxidation and protein acetylation show circadian rhythmicity (Masri et al. 2013), the link with $\mathrm{NAD}^{+}$availability through SIRT3 is of particular interest. Also, mitochondria from $\mathrm{Bmall}^{-1-}$ mice display reduced oxidative ability and decreased mitochondrial NAD ${ }^{+}$levels (Peek et al. 2013). These findings, together with the implication of SIRT1 in circadian control, raise the possibility that the sirtuins$\mathrm{NAD}^{+}$link with the clock may represent a critical molecular pathway to govern the process of aging.

The implication of nuclear sirtuins in clock function is multiple. SIRT1 is both nuclear and cytoplasmic whereas SIRT6 is exclusively nuclear and mostly chromatin bound, localized at transcriptionally active genomic loci. SIRT1 and SIRT6 operate through distinct mechanisms to coordinate the clock machinery in a differential manner and thereby delineate the circadian transcriptional output (Masri et al. 2014). Because of these different mechanisms of action, in the liver these two sirtuins coordinate circadian expression of distinct groups of genes. SIRT6 exerts its function by coordinating CLOCK:BMAL1 recruitment to specific chromatin sites (Masri et al. 2014). SIRT1, which is mostly nucleoplasmic and is recruited to chromatin only 'on demand', deacetylates histones and non-histone proteins. Among the non-histone targets of SIRT1 there are the clock proteins BMAL1 and PER2 (Asher et al. 2008; Hirayama et al. 2007). SIRT1 is also able 
to deacetylate MLL1, thereby controlling its methyltransferase activity. Thus, there is control in $\mathrm{H} 3 \mathrm{~K} 4$ tri-methylation through the cyclic oscillation of $\mathrm{NAD}^{+}$levels (Aguilar-Arnal et al. 2015).

SIRT1-mediated deacetylation also affects circadian levels of other metabolites besides $\mathrm{NAD}^{+}$. Specifically, intracellular acetyl-CoA levels are controlled by the clock through SIRT1-controlled deacetylation of the enzyme acetyl-CoA Synthetase 1 (AceCS1) (Sahar et al. 2014). This acetylation switch controls AceCS1 activity, leading to cyclic synthesis of acetyl-CoA (Fig. 1), that then is likely to influence the acetylation levels of histones and non-histone proteins (Sahar et al. 2014). In contrast, SIRT6 deacetylase activity seems to be efficient in removing long chain fatty acids from lysine residues (Jiang et al. 2013). In this respect it is noteworthy that not only on $\mathrm{NAD}^{+}$, but also on fatty acids, control the activity of SIRT6 (Feldman et al. 2013). Thus, SIRT6 appears to occupy a key position in the control of fatty acids metabolism by the clock. Indeed, CLOCK: BMAL1-driven activation of genes involved in fatty acid biosynthesis is modulated by SIRT6 (Masri et al. 2014).

High-throughput analysis of the transcriptome and metabolome along the circadian cycle has revealed notable differences in the metabolic functions of SIRT1 and SIRT6. Using mice with liver-specific deletion of either SIRT1 or SIRT6, a specific role for SIRT6 was shown in dictating the synthesis and breakdown of fatty acid pathways, as well as their storage into triglycerides. SIRT6 operates at least in part through the control of alternative circadian transcriptional pathways, specifically because of the chromatin recruitment of the sterol regulatory element-binding protein 1 (SREBP1) (Masri et al. 2014). Thus, it is through genomic partitioning that the two deacetylases contribute to a parallel segregation of cellular metabolism (Masri et al. 2014).

Finally, these findings suggest a role for genome topology in circadian control (Aguilar-Arnal et al. 2013). Our studies have identified the presence of circadian interactomes where co-regulated genes are physically associated in the circadian epigenome. Nuclear sirtuins may constitute a paradigm for other chromatin remodelers that could contribute in the cyclic control of the nuclear landscape. Also, specific changes in the nuclear localization of $\mathrm{NAD}^{+}$may provide the possibility of restricting the distribution of this metabolite to "niches" of activity (Katada et al. 2012).

\section{Conclusion}

The ability of the circadian clock machinery to sense the metabolic state of the cell in a time-specific manner places it in a strategic position. Indeed, fascinating findings reviewed in this article demonstrate the direct implication of the clock in the maintenance of cellular homeostasis. The clock machinery appears to integrate environmental and metabolic signals to directly translate them in plasticity in gene expression so to favor the adaptation of the organism to specific conditions. As the 
circadian transcriptional landscape is highly complex, including dynamic changes in nuclear organization (Katada et al. 2012; Aguilar-Arnal et al. 2013), it becomes critical to decipher how the nuclear landscape integrates metabolic cues and shapes the transcriptional output. It is through the analysis of the specific coordination that key chromatin remodelers have with clock transcription factors that we will gain insights into how the intracellular metabolic state communicates with the clock machinery. As disruption of clock function has been linked to a variety of pathological conditions, revealing the clock mechanisms will lead to innovative strategies towards the pharmacological treatment of metabolic syndromes, obesity, diabetes, inflammation and even cancer.

Acknowledgments Studies in the Center for Epigenetics and Metabolism are supported by the National Institute of Health, Merieux Research Grants, and INSERM (Institut National de la Sante et Recherche Medicale, France).

Open Access This chapter is distributed under the terms of the Creative Commons AttributionNoncommercial 2.5 License (http://creativecommons.org/licenses/by-nc/2.5/) which permits any noncommercial use, distribution, and reproduction in any medium, provided the original author(s) and source are credited.

The images or other third party material in this chapter are included in the work's Creative Commons license, unless indicated otherwise in the credit line; if such material is not included in the work's Creative Commons license and the respective action is not permitted by statutory regulation, users will need to obtain permission from the license holder to duplicate, adapt or reproduce the material.

\section{References}

Aguilar-Arnal L, Hakim O, Patel VR, Baldi P, Hager GL, Sassone-Corsi P (2013) Cycles in spatial and temporal chromosomal organization driven by the circadian clock. Nat Struct Mol Biol 20:1206-1213

Aguilar-Arnal L, Katada S, Orozco-Solis R, Sassone-Corsi P (2015) NAD ${ }^{+}$-SIRT1 control of H3K4 trimethylation through circadian deacetylation of MLL1. Nat Struct Mol Biol 22:312-318

Asher G, Sassone-Corsi P (2015) Time for food: the intimate interplay between nutrition, metabolism and the circadian clock. Cell 161:84-92

Asher G, Gatfield D, Stratmann M, Reinke H, Dibner C, Kreppel F, Mostoslavsky R, Alt FW, Schibler U (2008) SIRT1 regulates circadian clock gene expression through PER2 deacetylation. Cell 134:317-328

Bellet MM, Nakahata Y, Boudjelal M, Watts E, Mossakowska DE, Edwards KA, Cervantes M, Astarita G, Loh C, Ellis JL, Vlasuk GP, Sassone-Corsi P (2013) Pharmacological modulation of circadian rhythms by synthetic activators of the deacetylase SIRT1. Proc Natl Acad Sci USA 110:3333-3338

Busino L, Bassermann F, Maiolica A, Lee C, Nolan PM, Godinho SI (2007) SCFFbxl3 controls the oscillation of the circadian clock by directing the degradation of cryptochrome proteins. Science 316:900-904

Crosio C, Cermakian N, Allis CD, Sassone-Corsi P (2000) Light induces chromatin modification in cells of the mammalian circadian clock. Nat Neurosci 3:1241-1247 
Curtis AM, Seo SB, Westgate EJ, Rudic RD, Smyth EM, Chakravarti D, FitzGerald GA, McNamara P (2004) Histone acetyltransferase-dependent chromatin remodeling and the vascular clock. J Biol Chem 279:7091-7097

Dallmann R, Viola AU, Tarokh L, Cajochen C, Brown SA (2012) The human circadian metabolome. Proc Natl Acad Sci USA 109:2625-2629

DiTacchio L, Le HD, Vollmers C, Hatori M, Witcher M, Secombe J, Panda S (2011) Histone lysine demethylase JARID1a activates CLOCK-BMAL1 and influences the circadian clock. Science 333:1881-1885

Doi M, Hirayama J, Sassone-Corsi P (2006) Circadian regulator CLOCK is a histone acetyltransferase. Cell 125:497-508

Duffield GE, Best JD, Meurers BH, Bittner A, Loros JJ, Dunlap JC (2002) Circadian programs of transcriptional activation, signaling, and protein turnover revealed by microarray analysis of mammalian cells. Curr Biol 12:551-557

Duong HA, Robles MS, Knutti D, Weitz CJ (2011) A molecular mechanism for circadian clock negative feedback. Science 332:1436-1439

Eckel-Mahan K, Sassone-Corsi P (2013) Metabolism and the circadian clock converge. Physiol Rev 93:107-135

Eckel-Mahan KL, Patel VR, Mohney RP, Vignola KS, Baldi P, Sassone-Corsi P (2012) Coordination of the transcriptome and metabolome by the circadian clock. Proc Natl Acad Sci USA 109:5541-5546

Eckel-Mahan KL, Patel VR, de Mateo S, Orozco-Solis R, Ceglia NJ, Sahar S, Dilag-Penilla SA, Dyar KA, Baldi P, Sassone-Corsi P (2013) Reprogramming of the circadian clock by nutritional challenge. Cell 155:1464-1478

Etchegaray JP, Lee C, Wade PA, Reppert SM (2003) Rhythmic histone acetylation underlies transcription in the mammalian circadian clock. Nature 421:177-182

Etchegaray JP, Yang X, DeBruyne JP, Peters AH, Weaver DR, Jenuwein T, Reppert SM (2006) The polycomb group protein EZH2 is required for mammalian circadian clock function. J Biol Chem 281:21209-21215

Feldman JL, Baeza J, Denu JM (2013) Activation of the protein deacetylase SIRT6 by long-chain fatty acids and widespread deacylation by mammalian sirtuins. J Biol Chem 288:31350-31356

Feng D, Lazar MA (2012) Clocks, metabolism, and the epigenome. Mol Cell 47:158-167

Fustin JM, Doi M, Yamaguchi Y, Hida H, Nishimura S, Yoshida M, Isagawa T, Morioka MS, Kakeya H, Manabe I, Okamura H (2013) RNA-methylation dependent RNA processing controls the speed of the circadian clock. Cell 155:793-806

Gamble KL, Berry R, Frank SJ, Young ME (2014) Circadian clock control of endocrine factors. Nat Rev Endocrinol 10:466-475

Gomes AP, Price NL, Ling AJ, Moslehi JJ, Montgomery MK, Rajman L, White JP, Teodoro JS, Wrann CD, Hubbard BP, Mercken EM, Palmeira CM, de Cabo R, Rolo AP, Turner N, Bell EL, Sinclair DA (2013) Declining $\mathrm{NAD}(+)$ induces a pseudohypoxic state disrupting nuclearmitochondrial communication during aging. Cell 155:1624-1638

Hatori M, Vollmers C, Zarrinpar A, DiTacchio L, Bushong EA, Gill S, Leblanc M, Chaix A, Joens M, Fitzpatrick JA, Ellisman MH, Panda S (2012) Time-restricted feeding without reducing caloric intake prevents metabolic diseases in mice fed a high-fat diet. Cell Metab 15:848-860

Hebert AS, Dittenhafer-Reed KE, Yu W, Bailey DJ, Selen ES, Boersma MD, Carson JJ, Tonelli M, Balloon AJ, Higbee AJ, Westphall MS, Pagliarini DJ, Prolla TA, Assadi-Porter F, Roy S, Denu JM, Coon JJ (2013) Calorie restriction and SIRT3 trigger global reprogramming of the mitochondrial protein acetylome. Mol Cell 49:186-199

Hirano A, Yumimoto K, Tsunematsu R, Matsumoto M, Oyama M, Kozuka-Hata H, Nakagawa T, Lanjakornsiripan D, Nakayama KI, Fukada Y (2013) FBXL21 regulates oscillation of the circadian clock through ubiquitination and stabilization of cryptochromes. Cell 152:1106-1118 
Hirayama J, Sahar S, Grimaldi B, Tamaru T, Takamatsu K, Nakahata Y, Sassone-Corsi P (2007) CLOCK-mediated acetylation of BMAL1 controls circadian function. Nature 450:1086-1090

Hirota T, Lee JW, St John PC, Sawa M, Iwaisako K, Noguchi T, Pongsawakul PY, Sonntag T, Welsh DK, Brenner DA, Doyle FJ 3rd, Schultz PG, Kay SA (2012) Identification of small molecule activators of cryptochrome. Science 337:1094-1097

Jiang H, Khan S, Wang Y, Charron G, He B, Sebastian C, Du J, Kim R, Ge E, Mostoslavsky R, Hang HC, Hao Q, Lin HS (2013) SIRT6 regulates TNF-alpha secretion through hydrolysis of long-chain fatty acyl lysine. Nature 496:110-113

Jordan SD, Lamia KA (2013) AMPK at the crossroads of circadian clocks and metabolism. Mol Cell Endocrinol 366:163-169

Kaasik K, Kivimäe S, Allen JJ, Chalkley RJ, Huang Y, Baer K, Kissel H, Burlingame AL, Shokat KM, Ptáček LJ, Fu YH (2013) Glucose sensor O-GlcNAcylation coordinates with phosphorylation to regulate circadian clock. Cell Metab 17:291-302

Kasukawa T, Sugimoto M, Hida A, Minami Y, Mori M, Honma S, Honma K, Mishima K, Soga T, Ueda HR (2012) Human blood metabolite timetable indicates internal body time. Proc Natl Acad Sci USA 109:15036-15041

Katada S, Sassone-Corsi P (2010) The histone methyltransferase MLL1 permits the oscillation of circadian gene expression. Nat Struct Mol Biol 17:1414-1421

Katada S, Imhof A, Sassone-Corsi P (2012) Connecting threads: epigenetics and metabolism. Cell 148:24-28

Lee H, Chen R, Lee Y, Yoo S, Lee C (2009) Essential roles of CKIdelta and CKIepsilon in the mammalian circadian clock. Proc Natl Acad Sci USA 106:21359-21364

Lee Y, Lee J, Kwon I, Nakajima Y, Ohmiya Y, Son GH, Lee KH, Kim K (2010) Coactivation of the CLOCK-BMAL1 complex by CBP mediates resetting of the circadian clock. J Cell Sci 123:3547-3557

Li MD, Ruan HB, Hughes ME, Lee JS, Singh JP, Jones SP, Nitabach MN, Yang X (2013) O-GlcNAc signaling entrains the circadian clock by inhibiting BMAL1/CLOCK ubiquitination. Cell Metab 17:303-310

Masri S, Sassone-Corsi P (2010) Plasticity and specificity of the circadian epigenome. Nat Neurosci 13:1324-1329

Masri S, Patel VR, Eckel-Mahan KL, Peleg S, Forne I, Ladurner AG, Baldi P, Imhof A, SassoneCorsi P (2013) Circadian acetylome reveals regulation of mitochondrial metabolic pathways. Proc Natl Acad Sci USA 110:3339-3344

Masri S, Rigor P, Cervantes M, Ceglia N, Sebastian C, Xiao C, Roqueta-Rivera M, Deng C, Osborne TF, Mostoslavsky R, Baldi P, Sassone-Corsi P (2014) Partitioning circadian transcription by SIRT6 leads to segregated control of cellular metabolism. Cell 158:659-672

Mauvoisin D, Wang J, Jouffe C, Martin E, Atger F, Waridel P, Quadroni M, Gachon F, Naef F (2014) Circadian clock-dependent and -independent rhythmic proteomes implement distinct diurnal functions in mouse liver. Proc Natl Acad Sci USA 111:167-172

Nakahata Y, Kaluzova M, Grimaldi B, Sahar S, Hirayama J, Chen D, Guarente LP, Sassone-Corsi P (2008) The NAD ${ }^{+}$-dependent deacetylase SIRT1 modulates CLOCK-mediated chromatin remodeling and circadian control. Cell 134:329-340

Nakahata Y, Sahar S, Astarita G, Kaluzova M, Sassone-Corsi P (2009) Circadian control of the $\mathrm{NAD}^{+}$salvage pathway by CLOCK-SIRT1. Science 324:654-657

Nam HJ, Boo K, Kim D, Han DH, Choe HK, Kim CR, Sun W, Kim H, Kim K, Lee H, Metzger E, Schuele R, Yoo SH, Takahashi JS, Cho S, Son GH, Baek SH (2014) Phosphorylation of LSD1 by PKCalpha is crucial for circadian rhythmicity and phase resetting. Mol Cell 53:791-805

Naruse Y, Oh-hashi K, Iijima N, Naruse M, Yoshioka H, Tanaka M (2004) Circadian and lightinduced transcription of clock gene Per1 depends on histone acetylation and deacetylation. Mol Cell Biol 24:6278-6287

Panda S, Antoch MP, Miller BH, Su AI, Schook AB, Straume M, Schultz PG, Kay SA, Takahashi JS, Hogenesch JB (2002) Coordinated transcription of key pathways in the mouse by the circadian clock. Cell 109:307-320 
Peek CB, Affinati AH, Ramsey KM, Kuo HY, Yu W, Sena LA, Ilkayeva O, Marcheva B, Kobayashi Y, Omura C, Levine DC, Bacsik DJ, Gius D, Newgard CB, Goetzman E, Chandel NS, Denu JM, Mrksich M, Bass J (2013) Circadian clock NAD ${ }^{+}$cycle drives mitochondrial oxidative metabolism in mice. Science 342:1243417

Ramsey KM, Yoshino J, Brace CS, Abrassart D, Kobayashi Y, Marcheva B, Hong HK, Chong JL, Buhr ED, Lee C, Takahashi JS, Imai S, Bass J (2009) Circadian clock feedback cycle through NAMPT-mediated NAD ${ }^{+}$biosynthesis. Science 324:651-654

Ripperger JA, Schibler U (2006) Rhythmic CLOCK-BMAL1 binding to multiple E-box motifs drives circadian Dbp transcription and chromatin transitions. Nat Genet 38:369-374

Rutter J, Reick M, Wu LC, McKnight SL (2001) Regulation of clock and NPAS2 DNA binding by the redox state of NAD cofactors. Science 293:510-514

Sahar S, Masubuchi S, Eckel-Mahan K, Vollmer S, Galla L, Ceglia N, Masri S, Barth TK, Grimaldi B, Oluyemi O, Astarita G, Hallows WC, Piomelli D, Imhof A, Baldi P, Denu JM, Sassone-Corsi P (2014) Circadian control of fatty acid elongation by SIRT1 protein-mediated deacetylation of acetyl-coenzyme A synthetase 1. J Biol Chem 289:6091-6097

Schmalen I, Reischl S, Wallach T, Klemz R, Grudziecki A, Prabu JR, Benda C, Kramer A, Wolf E (2014) Interaction of circadian clock proteins CRY1 and PER2 is modulated by zinc binding and disulfide bond formation. Cell 157:1203-1215

Shyh-Chang N, Locasale JW, Lyssiotis CA, Zheng Y, Teo RY, Ratanasirintrawoot S, Zhang J, Onder T, Unternaehrer JJ, Zhu H, Asara JM, Daley GQ, Cantley LC (2013) Influence of threonine metabolism on S-adenosylmethionine and histone methylation. Science 339:222-226

Siepka SM, Yoo SH, Park J, Song W, Kumar V, Hu Y, Lee C, Takahashi JS (2007) Circadian mutant overtime reveals F-box protein FBXL3 regulation of cryptochrome and period gene expression. Cell 129:1011-1023

Storch KF, Lipan O, Leykin I, Viswanathan N, Davis FC, Wong WH, Weitz CJ (2002) Extensive and divergent circadian gene expression in liver and heart. Nature 417:78-83

Sun Z, Feng D, Everett LJ, Bugge A, Lazar MA (2011) Circadian epigenomic remodeling and hepatic lipogenesis: lessons from HDAC3. Cold Spring Harb Symp Quant Biol 76:49-55

Takahata $\mathrm{S}$ et al (2000) Transactivation mechanisms of mouse clock transcription factors, mClock and mArnt3. Genes Cells 5:739-747

Ueda HR, Chen W, Adachi A, Wakamatsu H, Hayashi S, Takasugi T, Nagano M, Nakahama K, Suzuki Y, Sugano S, Iino M, Shigeyoshi Y, Hashimoto S (2002) A transcription factor response element for gene expression during circadian night. Nature 418:534-539

Wellen KE, Hatzivassiliou G, Sachdeva UM, Bui TV, Cross JR, Thompson CB (2009) ATP-citrate lyase links cellular metabolism to histone acetylation. Science 324:1076-1080

Xing W, Busino L, Hinds TR, Marionni ST, Saifee NH, Bush MF, Pagano M, Zheng N (2013) SCF (FBXL3) ubiquitin ligase targets cryptochromes at their cofactor pocket. Nature 496:64-68

Yang H, Yang T, Baur JA, Perez E, Matsui T, Carmona JJ, Lamming DW, Souza-Pinto NC, Bohr VA, Rosenzweig A, de Cabo R, Sauve AA, Sinclair DA (2007) Nutrient-sensitive mitochondrial NAD+ levels dictate cell survival. Cell 130:1095-1107

Yoo SH, Mohawk JA, Siepka SM, Shan Y, Huh SK, Hong HK, Kornblum I, Kumar V, Koike N, Xu M, Nussbaum J, Liu X, Chen Z, Chen ZJ, Green CB, Takahashi JS (2013) Competing E3 ubiquitin ligases govern circadian periodicity by degradation of CRY in nucleus and cytoplasm. Cell 152:1091-1105

Zhang EE, Kay SA (2010) Clocks not winding down: unravelling circadian networks. Nat Rev Mol Cell Biol 11:764-776 